\title{
Autopsy as Gold Standard in FDG-PET Studies in Dementia
}

\author{
Pascali Durand-Martel, Dominic Tremblay, Catherine Brodeur, Nancy Paquet
}

\begin{abstract}
Positron emission tomography (PET) imaging with F18-fluorodeoxyglucose (FDG) is increasingly used as an adjunct to clinical evaluation in the diagnosis of dementia. Considering that most FDG-PET studies in dementia use clinical diagnosis as gold standard and that clinical diagnosis is approximately $80 \%$ sensitive or accurate, we aim to review the evidence-based data on the diagnostic accuracy of brain FDG-PET in dementia when cerebral autopsy is used as gold standard. We searched the PubMed and Medline databases for dementia-related articles that correlate histopathological diagnosis at autopsy with FDG-PET imaging and found 47 articles among which there were only 5 studies of 20 patients or more. We were able to conclude that sensitivity and specificity of FDG-PET for Alzheimer's disease are good, but more studies using histopathological diagnosis at autopsy as gold standard are needed in order to evaluate what FDG-PET truly adds to premortem diagnostic accuracy in dementia.
\end{abstract}

RÉSUMÉ: L'autopsie comme étalon or dans les études TEP-FDG dans la démence. La tomographie par émission de positrons (TEP) au F18-fluorodésoxyglucose est de plus en plus utilisée comme examen d'appoint de l'évaluation clinique dans le diagnostic de la démence. Comme la plupart des études TEP-FDG dans la démence utilisent le diagnostic clinique comme étalon or et que le diagnostic clinique a une sensibilité ou une exactitude d'environ $80 \%$, le but de notre étude était de revoir les données fondées sur des evidences au sujet de l'exactitude de la TEP-FDG du cerveau dans la démence quand l'autopsie cérébrale est utilisée comme étalon or. Nous avons effectué une recherche dans les bases de données PubMed et Medline afin de trouver les articles sur la démence qui évaluaient la corrélation entre le diagnostic histopathologique à l'autopsie et l'imagerie TEP-FDG. Nous avons identifié 47 articles dont seulement 5 portaient sur 20 patients ou plus. Nous avons pu conclure que la sensibilité et la spécificité de la TEP-FDG pour la maladie d'Alzheimer sont bonnes, mais qu'il faudra effectuer d'autres études utilisant le diagnostic histopathologique à l'autopsie comme étalon or pour évaluer ce que la TEP-FDG ajoute réellement à l'exactitude du diagnostic prémortem dans la démence.

Can. J. Neurol. Sci. 2010; 37: 336-342

Cognitive impairment is an area of great concern in the media and for clinicians around the world. In the past 20 years, many articles have been written about positron emission tomography (PET) imaging with F18-fluorodeoxyglucose (FDG), either to investigate its qualities as a diagnostic tool or, more recently, as inclusion criteria in clinical trials ${ }^{1}$. However, the routine use of FDG-PET in the investigation of dementia is not recommended in the guidelines published by the American Academy of Neurology ${ }^{2}$ or by the Third Canadian Consensus Conference on Dementia $^{3}$. Several publications have studied the ability of FDGPET to differentiate Alzheimer's disease (AD) from other dementia $^{4}$, most of them using clinical diagnosis as gold standard. However, to this day, clinical diagnosis, even when combined with extensive neuropsychological testing, is neither sensitive nor specific enough to be considered a gold standard in dementia. In studies of clinicopathological correlation, the sensitivity of clinical diagnosis for $\mathrm{AD}$ varies between 75 and $98 \%$, with an average of $82 \%$ when adjusted for the number of patients per study ${ }^{5-9}$. In clinicopathological correlation studies of 170 or more patients with a clinical diagnosis of $\mathrm{AD}$ the accuracy varies between $78 \%$ and $88 \%$, with an adjusted average of $81 \%{ }^{10-12}$. In 2006, Forman et al identified $21 \%$ of AD pathology in a series of 114 cases presenting clinically as frontotemporal dementia ${ }^{13}$. In other words, up to one out of five patients participating in FDG-PET studies could, in fact, present a pathology that is different from the one that was clinically

From the Neurology Service (PDM), Nuclear Medicine Department (DT, NP), Centre Hospitalier Universitaire de Sherbrooke, Sherbrooke; Geriatrics Service (CB), McGill University Health Centre, Montreal, Quebec, Canada.

Received August 7, 2009. Final Revisions Submitted November 10, 2009. Correspondence to: Nancy Paquet, 3001 12e Avenue N, Sherbrooke, Quebec, J1H 5N4, Canada. 
diagnosed. We believe that FDG-PET is a useful adjunctive diagnostic tool, but in order to evaluate what this exam truly adds to the accuracy of premortem diagnosis of dementing illnesses, we need to review the studies that use brain autopsy as gold standard. In this article, we present a systematic review of the correlations between FDG-PET and autopsy in literature.

\section{Methods}

Methods and results of our literature review are summarized in the Figure. On June 24th 2009 we searched the Pubmed database for relevant papers. First, we combined the entry "FDG" with "dementia", and then, in turn, with "Lewy Body disease", "frontotemporal lobar degeneration", "frontotemporal dementia", "Alzheimer", "Pick's disease", "progressive supranuclear palsy", "corticobasal degeneration", "semantic dementia", "primary progressive aphasia", "Parkinson's disease dementia", "vascular dementia" and "Creutzfeldt-Jakob". We repeated the same searches replacing "FDG" by "positron emission tomography". Titles and abstracts for each result were scanned for our inclusion criteria: presence and correlation of FDG-PET imaging and cerebral autopsy for the same patient(s). We excluded works if they: were written in languages other than English or French, reported the results of animal researches, did not used FDG as a tracer for PET, studied only mild cognitive impairment (MCI) or used clinical diagnosis, genetic testing or histopathological data from a brain biopsy as gold standard. Brain biopsy was excluded as a gold standard because it can overlook mild or mixed pathologies. We also excluded genetic testing as gold standard because most mutations known to be associated with dementia have important phenotypical variability and are rare occurrences. We also searched the Medline database for articles published between 1950 and June

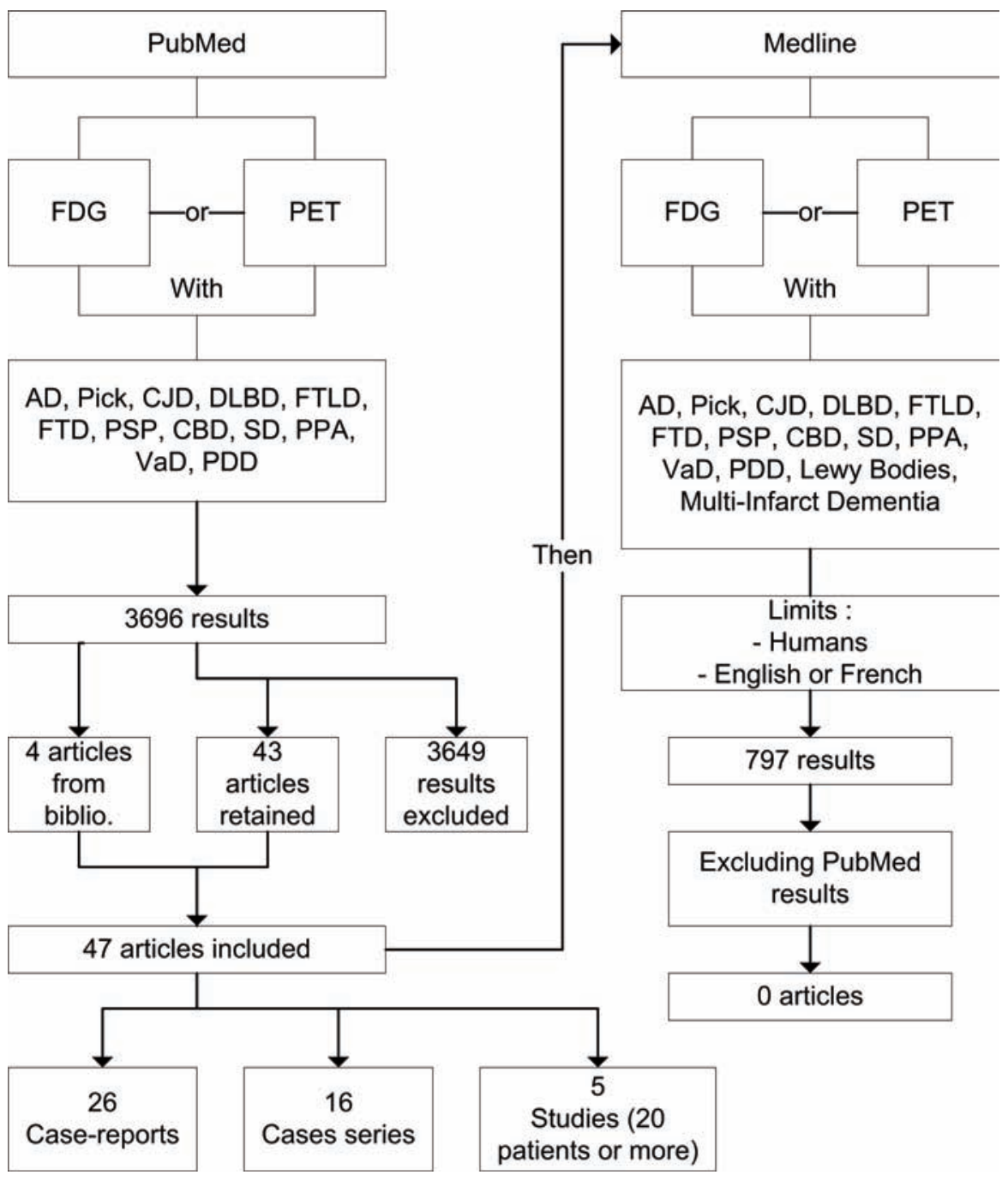

Figure: Literature review methodology and results. FDG = Fluorodeoxyglucose, PET = Positron Emission Tomography, AD = Alzheimer's disease, $C J D=$ Creutzfeldt-Jakob disease, DLBD = Diffuse Lewy Body disease, FTLD = frontotemporal lobar degeneration, FTD = frontotemporal dementia, $P S P=$ progressive supranuclear palsy, $C B D=$ corticobasal degeneration, $S D=$ semantic dementia, $P P A=$ primary progressive aphasia, VaD $=$ vascular dementia, $P D D=$ Parkinson's disease related dementia. 
24th 2009 corresponding to either "Positron Emission Tomography" or "Fluorodeoxyglucose F18" and either "Dementia", "Pick Disease of the Brain", "Creutzfeldt-Jakob Syndrome", "Lewy Bodies", "Lewy Body disease", "Alzheimer Disease", "Vascular Dementia", "Multi-Infarct Dementia", "Progressive Supranuclear Palsy", "Primary Progressive Aphasia", "corticobasal degeneration" (as keyword only (kwd)), "semantic dementia" (kwd), "Parkinson's disease dementia" (kwd), "frontotemporal lobar degeneration" (kwd) or "frontotemporal dementia" (kwd). We restricted this search to articles referring to humans that were written in English or in French and we scanned the results for the inclusion and exclusion criteria described above. Several studies and case series evaluated FDG-PET as well as other imaging techniques or included several patients for which the final diagnosis had been decided over different criteria. These articles were included in our study but we only considered the patients for which there had been both a FDG-PET and a cerebral autopsy.

\section{Results}

A total of 3696 results were obtained from PubMed and their titles and abstracts were scanned. Among these results, we initially selected 151 FDG-PET-related publications. After a complete reading of these articles and their references, 43 articles meeting our criteria remained. Four additional papers were found through the references of the initial 151 articles selection. The Medline search provided us with 797 results that were also scanned for the inclusion and exclusion criteria listed in the previous section. No additional publication was found through this database. The final number of articles included in this review is 47 .

Among these 47 articles, the overwhelming majority are case reports or series. Considering only the reported patients for which there has been both a FDG-PET and a cerebral autopsy, there are 26 single case reports, 16 case series that include between 4 and 11 patients, and only 5 studies of 20 patients or more. The Table summarizes these five studies and their results. The pathological diagnoses of the case reports are diverse. There are eight cases of prion diseases ${ }^{14-21}$, five isolated $\mathrm{AD}^{22-26}$, four frontotemporal lobar degeneration (FTLD) ${ }^{27-30}$, four pure diffuse Lewy body disease (DLBD) ${ }^{31-34}$, two mixed AD and DLBD ${ }^{35-36}$, two progressive supranuclear palsy ${ }^{37-38}$ and one Parkinson's disease $^{39}$. In contrast, most of the case series refer to patients with a pathological diagnosis of $\mathrm{AD}^{40-47}$ or to a group of patients presenting either $\mathrm{AD}$ or another diagnosis such as $\mathrm{DLBD}^{48}$ or FTLD $^{49}$. Among the remaining series, three present CreutzfeldtJakob disease cases ${ }^{50-52}$, two present progressive supranuclear palsy patients ${ }^{53-54}$ and one presents patients with frontotemporal lobar degeneration linked to chromosome 17 mutations ${ }^{55}$. One of the case series that reports Creutzfeldt-Jakob disease cases also presents a case of metachromatic leukodystrophy ${ }^{52}$. Two neuropathologically proven cases of Pick's disease and five of $\mathrm{AD}$ are also included in the series but we were unable to know whether a biopsy or an autopsy had occurred in all but one case of $\mathrm{AD}$ for which there had been a biopsy. Fortunately, one of the larger autopsy-only studies includes some patients from this series $^{56}$.

Four out of the five larger studies included between 20 and 45 patients. Hoffman et al evaluated the accuracy, sensitivity and specificity of bilaterally decreased glucose metabolism in the temporal and parietal lobes for Alzheimer's disease in a group of 20 patients recruited on the basis of a challenging or difficult clinical diagnosis ${ }^{57}$. In this paper, the analysis also included two patients whose diagnosis had been made with cerebral biopsy. The premortem clinical diagnoses are included in the publication. While, in this study, PET is more sensitive for AD than clinical diagnosis of probable and possible AD with the criteria of both the National Institute of Neurological and Communicative Disorders and Stroke and Alzheimer's Disease and Related Disorders Association (NINDS-ADRDA) and the Consortium to Establish a Registry for Alzheimer's Disease (CERAD) (92.9\% vs. $78.6 \%)$, its accuracy is equal $(81.8 \%$ vs. $81.8 \%$ ). In 2001, Minoshima et al studied the value of occipital hypometabolism ( $\mathrm{Z}$ score $\leq-2.4$ ) in differentiating DLBD from AD pathology ${ }^{58}$. The sensitivity and specificity were $90 \%$ and $80 \%$, respectively. They did a similar analysis with a group of clinically diagnosed AD among which some patients had developed clinical criteria for DLBD over time. F18fluorodeoxyglucose PET had been obtained before the patients presented symptoms suggestive of DLBD. The specificity was greater and the sensitivity was lower in this clinically diagnosed group, $95 \%$ and $38 \%$, respectively, with a $\mathrm{Z}$ score value of $\leq-2.5$.

The only two studies we found that evaluated the effect on diagnostic accuracy of adding an FDG-PET to the clinical evaluation are those of Jagust et al and Foster et al, both published in $2007^{59,60}$. The former classified patients as having AD or non-AD pathology on both PET and cerebral autopsy. In this study, the clinical evaluation made an average of 4.9 years before death was $76 \%$ sensitive and $58 \%$ specific for AD pathology, while the FDG-PET, obtained on average 3.6 years before death, was $84 \%$ sensitive and $74 \%$ specific. The likelihood of detecting AD pathology on the basis of the initial evaluation increased from $70 \%$ to $84 \%$ with the addition of a positive FDG-PET scan, and decreased to $31 \%$ with a negative scan. Foster et al evaluated six neurologists' interpretations of FDG-PET scans, as well as their clinical diagnoses made from clinical summaries and checklists created retrospectively from the files of 45 patients ${ }^{60}$. Thirty-one patients had a pathological diagnosis of AD while the remaining 14 had FTLD. The accuracy of FDG-PET was significantly better than that of clinical diagnosis $(p=0.02)$. There was an improvement of overall diagnostic accuracy from $79 \%$ to $90 \%(p=0.03)$ when raters added the PET results to their evaluation of clinical scenarios. In subgroup analysis however, this improvement was only statistically significant for FTLD patients $(\mathrm{p}=0.01)$, not for AD patients $(\mathrm{p}=0.3)$. The addition of PET was significantly more likely to have a beneficial rather than adverse effect on diagnostic accuracy $(\mathrm{p}=0.0001)$. It also increased significantly the diagnostic confidence in cases where the raters were uncertain about their initial diagnosis $(\mathrm{p}=0.003)$.

The largest PET-autopsy correlation study is that of Silverman et al, which includes 138 patients who underwent both FDG-PET and cerebral autopsy at eight different centers in the United States of America, Belgium and Germany ${ }^{56}$. The interpreters visually rated and classified the images according to several patterns of cerebral metabolism suggestive of either progressive or non progressive clinical course, and more specifically of AD. The premortem clinical diagnoses of these 
Table: Summary of the 5 studies correlating FDG-PET imaging with cerebral autopsy results in dementia

\begin{tabular}{|c|c|c|c|}
\hline Reference & Patients & Methods & Results \\
\hline $\begin{array}{l}\text { Hoffman, } \\
2000^{57}\end{array}$ & $\begin{array}{l}9 \text { AD only } \\
1 \text { AD + DLBD } \\
1 \text { AD + PSP } \\
9 \text { others, not AD } \\
\text { MMSE : unspecified }\end{array}$ & $\begin{array}{l}\text { Prospective, monocentric } \\
\text { PET to autopsy : } 2,1 \text { yrs average } \\
\text { PET : transaxial } \\
\text { Pathology : CERAD }\end{array}$ & $\begin{array}{l}\text { Ac for AD only : } 81,8 \% \\
\text { Se for AD only : } 92,9 \% \\
\text { Sp for AD only : } 62,5 \% \\
\text { Ac for AD + other pathology : } 81,8 \% \\
\text { Se for AD + other pathology }: 87,5 \% \\
\text { Sp for AD + other pathology : } 66,7 \%\end{array}$ \\
\hline $\begin{array}{l}\text { Minoshima, } \\
200158\end{array}$ & $\begin{array}{l}10 \mathrm{AD} \\
4 \mathrm{DLBD} \\
7 \mathrm{AD}+\mathrm{DLBD} \\
\mathrm{MMSE}: 14^{*}\end{array}$ & $\begin{array}{l}\text { Retrospective, monocentric } \\
\text { PET to autopsy : 3,2 yrs average } \\
\text { PET : 3D-SSP, Z score for visual cortex } \\
\text { Pathology : Khachaturian, Lewy bodies } \dagger\end{array}$ & $\begin{array}{l}\text { Ac for DLBD : N/A } \\
\text { Se for DLBD : } 90 \% \\
\text { Sp for DLBD : } 80 \%\end{array}$ \\
\hline $\begin{array}{l}\text { Jagust, } \\
2007^{59}\end{array}$ & $\begin{array}{l}25 \mathrm{AD} \\
19 \text { non } \mathrm{AD} \\
\mathrm{MMSE}: 23+/-5.7\end{array}$ & $\begin{array}{l}\text { Retrospective, monocentric } \\
\text { PET to autopsy : } 3,6 \text { yrs average } \\
\text { PET : axial, sagittal and coronal } \\
\text { Pathology : CERAD and NIA-Reagan }\end{array}$ & $\begin{array}{l}\text { Ac }: \text { N/A } \\
\text { Se for AD : } 84 \% \\
\text { Sp for AD : } 74 \% \\
\text { PPV for AD }: 81 \% \\
\text { NPV for AD : } 78 \%\end{array}$ \\
\hline $\begin{array}{l}\text { Foster, } \\
2007^{60}\end{array}$ & $\begin{array}{l}31 \text { AD } \\
14 \text { FTLD } \\
\text { MMSE : } 14+/-8.8\end{array}$ & $\begin{array}{l}\text { Retrospective, monocentric } \\
\text { PET to autopsy : N/A } \\
\text { PET : transaxial and SSP } \\
\text { Pathology : NIA-Reagan, FTLD } \\
\text { unspecified }\end{array}$ & $\begin{array}{l}\text { Ac of SSP : } 89,2 \% \\
\text { Se of SSP for AD : } 97,6 \% \\
\text { Sp of SSP for AD : } 73,2 \% \\
\text { PPV of SSP for AD : } 89 \% \\
\text { NPV of SSP for AD : } 93 \%\end{array}$ \\
\hline $\begin{array}{l}\text { Silverman, } \\
200156\end{array}$ & $\begin{array}{l}97 \text { AD }+/- \text { other pathology } \\
23 \text { other pathologies } \\
18 \text { no pathology } \\
\text { MMSE : } 24+/-6(\mathrm{~N}=85)\end{array}$ & $\begin{array}{l}\text { Multicentric } \\
\text { PET to autopsy : } 2,9 \text { yrs average } \\
\text { PET : axial and coronal } \\
\text { Pathology : Varied, unspecified }\end{array}$ & $\begin{array}{l}\text { Ac for AD : } 88 \% \\
\text { Se for AD : } 94 \% \\
\text { Sp for AD : } 73 \% \\
\text { Se for any degenerative disease : } 94 \% \\
\text { Sp for any degenerative disease : } 78 \%\end{array}$ \\
\hline
\end{tabular}

$\mathrm{AD}=$ Alzheimer's disease, DLBD $=$ Diffuse Lewy Body disease, $\mathrm{PSP}=$ progressive supranuclear palsy, MMSE $=$ Minimental Status Examination, FTLD = frontotemporal lobar degeneration, Ac = accuracy, Se = sensitivity, Sp = specificity, CERAD = Consortium to Establish a Registry for Alzheimer's disease, NIA = National Institute on Aging, N/A = Not available, $\mathrm{PPV}=$ positive predictive value, $\mathrm{NPV}=$ negative predictive value, $3 \mathrm{D}=$ three dimensional, $\mathrm{SSP}=$ stereotactic surface projection, *Adjusted mean calculated by the authors of this review, $\uparrow 3$ Lewy bodies per x 20 field in 4 fields in 3 of transentorhinal cortex, anterior, cingulate cortex, amygdala, and insular cortex

patients are unfortunately not discussed in the article, but information about the severity of cognitive impairment at the moment of FDG-PET is available. This allowed the authors to separately analyze a subgroup of 55 patients with mild or questionable dementia at the time of the PET scan, giving $89 \%$ accuracy, $95 \%$ sensitivity and $71 \%$ specificity.

The five main studies used different pathological criteria for Alzheimer's disease but all the criteria used are well recognised and validated. None of the five main studies mentioned whether the pathologists were blind to the results of the FDG-PET studies. As for PET reading, the techniques were also varied. In Minoshima et al, mean regional reduction in metabolism is measured in percentages for each group (AD, DLBD and Lewy Body variant $\mathrm{AD}$ ), and $\mathrm{Z}$ scores were chosen in order to optimize sensibility and sensitivity for DLBD ${ }^{58}$. In the four other papers, exams were classified into diagnostic categories by the investigators. The patterns for these categories are described in each article, with $\mathrm{AD}$ patterns usually corresponding to bilateral parietal, temporal and/or posterior cingulate hypometabolism. The specific proportion of regional metabolic reduction considered as threshold for significance is not mentioned in any study. In Foster et al, the mean inter-rater kappa for stereotactic surface projection (SSP) interpretation is $0.78^{60}$. In Silverman et al, 68 out of the 138 exams, each read by a single physician, were re-interpreted by a blinded nuclear medicine specialist who agreed with the initial diagnostic classification in all but one case $^{56}$. In the two remaining papers, exams were either interpreted by a single physician ${ }^{57}$ or by two investigators who had to come to a consensus ${ }^{59}$. We did not find any reported case or series with pathological confirmation of diagnosis where automated analysis of FDG-PET, as with the method developed by Heiss, in Herholz et $\mathrm{al}^{61}$, was used. The use of those automated techniques would limit inter-observer variability although it is presently unclear whether it would improve the overall sensitivity and specificity for AD.

\section{Discussion}

The purpose of our review was to verify whether studies using autopsy as gold standard have proven that FDG-PET improves the premortem diagnostic accuracy of dementia. The five larger studies we found fulfilling our criteria provide interesting information on the accuracy of FDG-PET diagnosis from a total of 268 patients. The results for accuracy, sensitivity and specificity for AD in these papers are in fact similar to those obtained in FDG-PET studies that use clinical diagnosis as gold standard ${ }^{4}$. This finding is reassuring because Alzheimer's disease 
is the most common cause of dementia in developed countries. Even though there currently is no pharmacological treatment that can reverse or stop biological progression of AD, acetylcholinesterase inhibitors as well as $\mathrm{N}$-methyl D-aspartate (NMDA) antagonists provide symptomatic relief, and hence improve quality of life while decreasing caregiver burden ${ }^{62-63}$. Diagnosis of DLBD and FTLD by PET appears accurate and sensitive, but since we found only 11 and 14 cases, respectively, in large studies we cannot make valid conclusions. Through this review, we also realised that there is little information available on the usefulness of FDG-PET for diseases other than AD, even in articles using clinical diagnosis as gold standard.

Unfortunately, only two out of the five studies that we found analysed the effect of combining FDG-PET with clinical evaluation. Hoffman et $\mathrm{al}^{57}$, Jagust et $\mathrm{al}^{59}$ and Silverman et $\mathrm{al}^{56}$ studied the diagnostic accuracy for AD in subjects with different pathological diagnosis but, since the PET results were dichotomized as AD or non-AD, or progressive vs non progressive, calculation of the overall accuracy is not possible. We have not found any study that evaluated prospectively the accuracy of FDG-PET for differentiating the various dementia subtypes. While Alzheimer's disease is part of the differential diagnosis in most cases, $\mathrm{AD}$ vs. non $\mathrm{AD}$ is not the only dilemma that clinicians interested in cognitive impairment face in their practice. The clinical and pathological diagnoses were also dichotomized in the evaluations of the adjunctive effect of PET on diagnostic accuracy by Jagust et $\mathrm{al}^{59}$ and by Foster et $\mathrm{al}^{60}$. This limits the application of their results to our clinical practice. Additionally, in Foster et al, the FDG-PET studies were interpreted by neurologists instead of nuclear medicine specialists or radiologists and the examiners could only interpret these studies as suggestive of either AD or FTLD ${ }^{60}$. We believe that these features, as well as the use of clinical vignettes that include even late presenting symptoms do not represent clinicians' reality.

In Jagust et al, initial clinical diagnosis was proven to be inferior to the latest diagnosis in life after a long-term followup $^{59}$. Conversely, Silverman et al noted a slight superiority of FDG-PET diagnosis in a subgroup of only mildly affected individuals ${ }^{56}$. This would argue in favour of adding FDG-PET exams to the initial evaluation of patients presenting with dementia in order to achieve better accuracy earlier in the course of the disease. In a case series by Mosconi et al, four normal elderly were followed clinically and with FDG-PET to the onset of clinically probable AD in two cases and amnesic MCI in the two others ${ }^{47}$. Alzheimer's disease changes were present at autopsy for these four patients and preclinical as well as early changes on the FDG-PET had been detected in all of them. Several papers report cohorts of MCI patients in which FDGPET is a good indicator of progression towards clinically probable AD. However, in order to truly identify and measure the benefits of FDG-PET early in the clinical course, there needs to be a multi-center and, ideally, prospective autopsy correlation study of a large population with varied pathological diagnoses in which the collected data include both initial and follow-up standardised clinical diagnoses, pharmacological treatment information, as well as FDG-PET results that are categorized into dementia subtypes instead of dichotomized. If such a study brought positive results, clinicians would have to take into consideration the cost of the exam, which varies from one center to another. As an example, the estimated cost of an FDG-PET in Quebec was below 1000 \$ in $2001^{64}$.

Our review has some limitations. First, we did not consider works that were either published in languages other than English or French, later than June 24th 2009, or in sources not accounted for in PubMed and Medline. Second, as in most literature review, we present studies with varied samples and methods. In these studies, both FDG-PET and autopsy have been made and interpreted by many different techniques and investigators, limiting our ability to compare their results. One might argue that in reviewing only FDG-PET studies, we overlooked the contribution of single photon emission computed tomography (SPECT) studies in dementia. However, the accuracy of PET has been proven to be superior to that of SPECT $^{2-65-67}$. We also overlooked amyloid, dopaminergic and other PET tracers, but these are not currently available to most clinicians in Canada. It is also possible to use visual or automated rating of hippocampal atrophy on magnetic resonance imaging (MRI) in the evaluation of patients with possible Alzheimer's disease. Advantages of this technique are greater availability of MRI compared to PET and the possibility to evaluate combined vascular lesions. The principal disadvantage is that hippocampal volume decrease occurs after the diminution of glucose metabolism which might make a single exam less useful than FDG-PET in MCI and early dementia $^{2}$. In one extensive literature review, the sensitivity of this technique varied between 35 and $95 \%$ (with most values between 76 and 95\%) and the specificity between 76 and $94 \%$, compared to clinical diagnosis ${ }^{68}$. These results seem comparable to FDG-PET. However, while there is fair evidence to support selective use of structural MRI or computed tomography in the evaluation of dementia patients, the actual usefulness of morphometric MRI implies serial measurements in order "to track the progression of AD in clinical trials (Grade B, Level 2)"69. Finally, we are confident that our search was thorough and that our inclusion and exclusion criteria allowed us to select only those FDG-PET and dementia studies that were clinically significant and used the appropriate gold standard.

Among the excluded articles, two are worth mentioning. We excluded an article by Tedeschi et al in which all the histological diagnoses were obtained through frontal biopsy ${ }^{70}$. Even though we believe that a single diagnosis made from a biopsy is reliable, it is likely that mixed pathologies would be missed by these procedures, and grading is unreliable. Finally, we excluded a study of medical statistics published in 2004 that was based on data from a study with a principal investigator, population, methods and results entirely identical to Foster et $\mathrm{al}^{60}$. This article provided us with no additional information that was related to our objective and we believed it was most likely from the same sample as Foster et al, even though it was published earlier.

\section{Conclusion}

In conclusion, there are few studies that compare FDG-PET results with autopsy diagnoses in dementia. The studies we found show good accuracy and sensitivity for Alzheimer's disease pathology, including in the early clinical stages when it is the most clinically valuable. This argues in favour of adding FDG-PET exams to the initial evaluation of patients presenting with atypical dementia in order to achieve better accuracy earlier 
in the course of the disease, and hence provide them the most appropriate treatment. The guidelines published by the Third Canadian Consensus Conference on Dementia in 2007 state that "there is fair evidence that functional imaging with PET or SPECT scanning might assist specialists in the differential diagnosis of dementia, particularly those with questionable early stage dementia or those with FTD (Grade B, Level 2) ${ }^{3}$ ". However, only one study investigates the accuracy and sensitivity for each DLBD and FTLD. No PET-autopsy study includes more than two major clinical subtypes of dementia in order to evaluate the overall accuracy of FDG-PET in a group of patients with many different clinical diagnoses. Even if it is reassuring that the results for $\mathrm{AD}$ in these papers are similar to those obtained from studies using clinical diagnosis as gold standard, we believe further studies with autopsy confirmation of diagnosis are needed in the field of PET and dementia.

\section{REFERENCES}

1. Chertkow $\mathrm{H}$, Black $\mathrm{S}$. Imaging biomarkers and their role in dementia clinical trials. Can J Neurol Sci. 2007;34 Suppl 1: $77-83$.

2. Knopman DS, DeKosky ST, Cummings JL, Chui H, Corey-Bloom J, Relkin N, et al. Practice parameters: diagnosis of dementia (an evidence-based review): report of the Quality Standards Subcommittee of the American Academy of Neurology. Neurology. 2001;56:1143-53.

3. Borrie M. Functional neuroimaging in the diagnosis of dementia. Alzheimers Dement. 2007;3:336-40.

4. Silverman DHS. Brain 18F-FDG PET in the diagnosis of neurodegenerative dementias: comparison with perfusion SPECT and with clinical evaluations lacking nuclear imaging. J Nucl Med. 2004:45:594-607.

5. Blacker D, Albert MS, Bassett SS, Go RC, Harrell LE, Folstein MF. Reliability and validity of NINCDS-ADRDA criteria for Alzheimer's disease. Arch Neurol. 1994;51:1198-1204.

6. Lim A, Tsuang D, Kukull W. Clinico-neuropathological correlation of Alzheimer's disease in a community-Based case series. J Am Geriatr Soc. 1999;47:564-9.

7. Lopez OL, Litvan I, Catt KE, Stowe R, Klunk W, Kaufer DI, et al. Accuracy of four clinical diagnostic criteria for the diagnosis of neurodegenerative dementias. Neurology. 1999;53(6):1292-9.

8. Massoud F, Devi G, Stern Y, Lawton A, Goldman JE, Liu Y, et al. A clinicopathological comparison of community-based and clinic-based cohorts of patients with dementia. Arch Neurol. 1999;56:1368-73.

9. Victoroff J, Mack WJ, Lyness SA, Chui HC. Multicenter clinicopathological correlation in dementia. Am J Psychiatry. 1995;152(10):1476-84.

10. Becker JT, Boller F, Lopez OL, Saxton J, McGonigle KL. The natural history of Alzheimer's disease: description of study cohort and accuracy of diagnosis. Arch Neurol. 1994;51:585-94.

11. Klatka LA, Schiffer RB, Powers JM, Kazee AM. Incorrect diagnosis of Alzheimer's disease: a clinicopathologic study. Arch Neurol. 1996;53:35-42.

12. Mendez MF, Mastri AR, Sung JH, Frey WH 2nd. Clinically diagnosed AD: neuropathologic findings in 650 cases. Alzheimer Dis Assoc Disord. 1992;6:35-43.

13. Forman MS, Farmer J, Johnson JK, Clark CN, Arnold SE, Koslett $\mathrm{HB}$, et al. Frontotemporal dementia: clinicopathological correlations. Ann Neurol. 2006;59:952-62.

14. Friedland RP, Prusiner SB, Jagust WJ, Budinger TF, Davis RL. Bitemporal hypometabolism in Creutzfeldt-Jakob disease measured by positron emission tomography with [18F]-2fluorodeoxyglucose. J Comput Assist Tomogr. 1984;8:978-81.

15. Goldman S, Liard A, Flament-Durand J, Luxen A, Bidaut LM, Stanus E, et al. Positron emission tomography and histopathology in Creutzfeldt-Jakob disease. Neurology. 1993; 43:1828-30.
16. Matochik JA, Molchan SE, Zametkin AJ, Warden DL, Sunderland T, Cohen RM. Regional cerebral glucose metabolism in autopsyconfirmed Creutzfeldt-Jakob disease. Acta Neurol Scand. 1995; 91:153-7.

17. Ogawa T, Inugami A, Fujita H, Hatazawa J, Shimosegawa E, Kanno I, et al. Serial positron emission tomography with fludeoxyglucose F18 in Creutzfeldt-Jakob disease. Am J Neuroradiol. 1995;16:978-81.

18. Holthoff VA, Sandmann J, Pawlik G, Schröder R, Heiss WD. Positron emission tomography in Creutzfeldt-Jakob disease. Arch Neurol. 1990;47:1035-8.

19. Tanaka Y, Minematsu K, Moriyasu H, Yamaguchi T, Yutani C, Kitamoto $\mathrm{T}$, et al. A Japanese family with a variant of Gerstmann-Sträussler-Scheinker disease. J Neurol Neurosurg Psychiatry. 1997;62:454-7.

20. Hamaguchi T, Kitamoto T, Sato T, Mizusawa H, Nakamura Y, Noguchi M, et al. Clinical diagnosis of MM2-type sporadic Creutzfeldt-Jakob disease. Neurology. 2005;64:643-8.

21. Pichler R, Ciovica I, Rachinger J, Weiss S, Aichneir FT. Multitracer study in Heidenhain variant of Creutzfeldt-Jakob disease: mismatch pattern of cerebral hypometabolism and perfusion imaging. Neuro Endocrinol Lett. 2008;29:67-8.

22. McGeer PL, Kamo H, Harrop R, McGeer EG, Martin WR, Pate BD, et al. Comparison of PET, MRI and CT with pathology in a proven case of Alzheimer's disease. Neurology. 1986;36: $1569-74$

23. McGeer PL, Kamo H, Harrop R, Li DK, Tuokko H, McGeer EG, et al. Positron emission tomography in patients with clinically diagnosed Alzheimer's disease. CMAJ. 1986;134:597-607.

24. Kempler D, Metter EJ, Riege WH, Jackson CA, Benson DF, Henson WR. Slowly progressive aphasia: three cases with language, memory, CT and PET data. J Neurol Neurosurg Psychiatry. 1990;53:987-93.

25. Mega MS, Chen SS, Thompson PM, Woods RP, Karaca TJ, Tiwari A, et al. Mapping histology to metabolism: coregistration of stained whole-brain sections to premortem PET in Alzheimer's disease. Neuroimage. 1997;5:147-53.

26. Kile SJ, Ellis WG, Olichney JM, Farias S, DeCarli C. Alzheimer abnormalities of the amygdala with Klüver-Bucy syndrome symptoms. Arch Neurol. 2009;66(1):125-9.

27. Kamo H, McGeer PL, Harrop R, McGeer EG, Kalne DB, Martin WR, et al. Positron emission tomography and histopathology in Pick's disease. Neurology. 1987;37(3):439-45.

28. Friedland RP, Koss E, Lerner A, Hedera P, Ellis D, Dronkers N, et al. Functional imaging, the frontal lobes and dementia. Dementia. 1993;4:192-203

29. Murrel JR, Spillantini MG, Zolo P, Guazzelli M, Smith MJ, Hasegawa M, et al. Tau gene mutation G389R causes a tauopathy with abundant Pick body-like inclusions and axonal deposits. J Neuropathol Exp Neurol. 1999;58(12):1207-26.

30. Spina S, Murrel JR, Huey ED, Wassermann EM, Pietrini P, Grafman J, et al. Corticobasal syndrome associated with the A9D progranulin mutation. J Neuropathol Exp Neurol. 2007;66(10): 892-900.

31. Higuchi M, Tashiro M, Arai H, Okamura N, Hara S, Higuchi S, et al. Glucose hypometabolism and neuropathological correlates in brains of dementia with Lewy bodies. Exp Neurol. 2000;162: 247-56.

32. Tatlidil R, New P, Mayberg H. FDG positron emission tomography in diffuse Lewy Body disease; a case report. Clin Nucl Med. 2000;25:1004-6.

33. Hisanaga K, Suzuki H, Tanji H, Mochizuki H, Iwasaki Y, Sato N, et al. Fluoro-DOPA and FDG positron emission tomography in a case of pathologically verified pure diffuse Lewy Body disease. J Neurol. 2001;248:905-6.

34. Bacskai BJ, Frosch MP, Freeman SH, Raymond SB, Augustinack JC, Johnson KA, et al. Molecular imaging with Pittsburg Compound B confirmed at autopsy. Arch Neurol. 2007;64: 431-4.

35. Okamura N, Arai H, Higuchi M, Tashiro M, Matsui T, Hu XS, et al. [18F]FDG-PET study in dementia with Lewy bodies and Alzheimer's disease. Prog Neuropsychopharmacol Biol Psychiatry. 2001;25:447-56. 
36. Gerstner E, Lazar RM, Keller C, Honig LS, Lazar GS, Marshall RS. A case of progressive apraxia of speech in pathologically verified Alzheimer's disease. Cogn Behav Neurol. 2007;20: 15-20.

37. Stanford PM, Halliday GM, Brooks WS, Kwok JB, Storey CE, Creazy H, et al. Progressive supranuclear palsy pathology caused by a novel silent mutation in exon 10 of the tau gene. Brain. 2000;123:880-93.

38. Mizuno T, Shiga K, Nakata Y, Nagura J, Nakase T, Ueda Y, et al. Discrepancy between clinical and pathological diagnoses of CBD and PSP. J Neurol. 2005;252:687-97.

39. Shapiro MB, Pietrini P, Grady CL, Ball MJ, DeCarli C, Kumar A, et al. Reductions in parietal and temporal cerebral metabolic rates for glucose are not specific for Alzheimer disease. J Neurol Neurosurg Psychiatry. 1993;56:859-64.

40. Akiyama H, Harrop R, McGeer PL, Peppard R, McGeer EG. Crossed cerebellar and uncrossed thalamic diaschisis in Alzheimer's disease. Neurology. 1989;39:541-8.

41. McGeer EG, McGeer PL, Akiyama H, Harrop R. Cortical glutaminase, beta-glucuronidase and glucose utilization in Alzheimer's disease. Can J Neurol Sci. 1989;16 Suppl 4:511-5.

42. McGeer EG, Peppard RP, McGeer PL, Tuokko H, Crockett D, Parks $\mathrm{R}$, et al. 18Fluorodeoxyglucose positron emission tomography studies in presumed Alzheimer's cases, including 13 serial scans. Can J Neurol Sci. 1990;17:1-11.

43. Peppard RF, Martin WR, Clark CM, Karr GD, McGeer PL, Kalne DB. Cortical glucose metabolism in Parkinson's and Alzheimer's disease. J Neurosci Res. 1990;27:561-8.

44. Barker WW, Yoshii F, Lowenstein DA, Chang JY, Apicella A, Pascal S, et al. Lack of correlation of regional neuropathology to the regional PET metabolic deficits in Alzheimer's disease. J Cereb Blood Flow Metab. 1991;11 Suppl 2:19.

45. DeCarli C, Atack JR, Ball MJ, Kay JA, Grady CL, Fewster P, et al. Post-mortem neurofibrillary tangle densities but not senile plaque densities are related to regional metabolic rates for glucose during life in Alzheimer's disease patients. Neurodegeneration. 1992;1:113-21.

46. Mielke R, Schröder R, Fink GR, Kessler J, Herholz K, Heiss W. Regional cerebral glucose metabolism and postmortem pathology in Alzheimer's disease. Acta Neuropathol. 1996;91:174-9.

47. Mosconi L, Mistur R, Switalski R, Tsui WH, Glodzik L, Li Y, et al. FDG-PET changes in brain glucose metabolism from normal cognition to pathologically verified Alzheimer's disease. Eur J Nucl Med Mol Imaging. 2009;36:811-22.

48. Albin RL, Minoshima S, D’Amato CJ, Frey KA, Kuhl DA, Sima AA. Fluoro-deoxyglucose positron emission tomography in diffuse Lewy body disease. Neurology. 1996;47:462-6.

49. Nestor PJ, Balan K, Cheow HK, Fryer TD, Knibb JA, Xuereb JH, et al. Nuclear imaging can predict pathologic diagnosis in progressive nonfluent aphasia. Neurology. 2007;68:238-9.

50. Henkel K, Zerr I, Hertel A, Gratz KF, Shröter A, Tschampa HJ, et al. Positron emission tomography with $[18 \mathrm{~F}] \mathrm{FDG}$ in the diagnosis of Creutzfeldt-Jakob disease (CJD). J Neurol. 2002; 249:699-705.

51. Engler H, Lundberg PO, Ekbom K, Nennesmo I, Nilsson A, Berström $\mathrm{M}$, et al. Multitracer study with positron emission tomography in Creutzfeldt-Jakob disease. Eur J Nucl Med Mol Imaging. 2003;30:85-95.

52. Salmon E, Sadzot B, Maquet P, Degueldre C, Lemaire C, Rigo P, et al. Differential diagnosis of Alzheimer's disease with PET. J Nucl Med. 1994;35:391-8.

53. Foster NL, Gilman S, Berent S, Sima AAF, D'Amato C, Koeppe $\mathrm{RA}$, et al. Progressive subcortical gliosis and progressive supranuclear palsy can have similar clinical and PET abnormalities. J Neurol Neurosurg Psychiatry. 1992;55:707-13.
54. Mishina M, Ishii K, Mitani K, Ohiama M, Yamazaki M, Ishiwata K, et al. Midbrain hypometabolism as early diagnostic sign for progressive supranuclear palsy. Acta Neurol Scand. 2004;110: $128-35$.

55. Arvanitakis Z, Witte RJ, Dickson DW, Tsuboi Y, Uitti RJ, Slowinski $\mathrm{J}$, et al. Clinical-pathologic study of biomarkers in FTDP-17 (PPND family with $\mathrm{N} 279 \mathrm{~K}$ tau mutation). Parkinsonism Relat Disord. 2007;13:230-9.

56. Silverman DHS, Small GW, Chang CY, Lu CS, Kung De Abarto MA, Chen W, et al. Positron emission tomography in evaluation of dementia; regional brain metabolism and long-term outcome. JAMA. 2001;286:2120-7.

57. Hoffman JM, Welsh-Bohmer KA, Hanson M, Krain B, Hulette C, Earl N, et al. FDG PET imaging in patients with pathologically verified dementia. J Nucl Med. 2000;41:1920-8.

58. Minoshima S, Foster NL, Sima AAF, Frey KA, Albin RL, Kuhl DE. Alzheimer's disease versus dementia with Lewy bodies: cerebral metabolic distinction with autopsy confirmation. Ann Neurol. 2001;50:358-65.

59. Jagust W, Reed B, Mungas D, Ellis W, DeCarli C. What does fluorodeoxyglucose PET imaging add to a clinical diagnosis of dementia? Neurology. 2007:69:871-7.

60. Foster NL, Heidebrink JL, Clark CM, Jagust WJ, Arnold SE, Barbas NR, et al. FDG-PET improves accuracy in distinguishing frontotemporal dementia and Alzheimer's disease. Brain. 2007; 130:2616-35.

61. Herzholz K, Salmon E, Perani D, Baron JC, Holthoff V, Frölich L, et al. Discrimination between Alzheimer dementia and controls by automated analysis of multicenter FDG PET. Neuroimage. 2002;17:302-16

62. Raina P, Santaguida P, Ismaila A, Patterson C, Cowan D, Levine N, et al. Effectiveness of cholinesterase inhibitors and memantine for treating dementia: evidence review for a clinical practice guideline. Ann Intern Med. 2008;148:379-97.

63. Gagnon M, Rive B, Hux M, Guilhaume C. Cost-effectiveness of memantine compared with standard care in moderate to severe Alzheimer disease in Canada. Can J Psychiatry. 2007;52(8): 519-26.

64. Dusseault FP, Nguyen VH, Ratchet F. La tomographie par émission de positrons au Québec. Québec (Canada): Agence d'évaluation des technologies et des modes d'intervention en santé; 2001 oct. Report No: AÉTMIS 01-3 RF. Rapport présenté au ministre délégué à la recherche, à la science et à la technologie du Québec.

65. Paquet N, Primeau F, Paradis V, Routhier G, Simard M, Bouchard RW. Comparative value of $99 \mathrm{mTc}-\mathrm{ECD}$ SPECT and $18 \mathrm{FDG}$ PET in atypical dementia: a pilot study with longitudinal followup. Eur J Nucl Med. 2008;35:S315.

66. Silverman DH, Small GW, Phelps ME. Clinical value of neuroimaging in the diagnosis of dementia. Sensitivity and specificity of regional cerebral metabolic and other parameters for early identification of Alzheimer's disease. Clin Positron Imaging. 1999;2:119-30.

67. Massa C, Perani D, Lucignani G, Zenorini A, Zito F, Rizzo G, et al. High-resolution Technetium-99m-HMPAO SPECT in patients with probable Alzheimer's disease: comparaison with Fluorine18-FDG PET. J Nucl Med. 1994;35:210-6.

68. Wahlund LO, Almkvist O, Blennow K, Engedahl K, Johansson A, Waldemar $\mathrm{G}$, et al. Evidence-based evaluation of magnetic resonance imaging as a diagnostic tool in dementia workup. Top Magn Reson Imaging. 2005;16:427-37.

69. Chow T. Structural neuroimaging in the diagnosis of dementia. Alzheimers Dement. 2007;3:333-5.

70. Tedeschi E, Hasselbalch SG, Waldemar G, Juhler M, Høgh P, Holm $\mathrm{S}$, et al. Heterogenous cerebral glucose metabolism in normal pressure hydrocephalus. J Neurol Neurosurg Psychiatry. 1995; 59:608-15. 